\title{
IMPACTS OF COVID-19 ON THE WORLD ECONOMY AND SOCIETIES: TOWARDS A NEW SOCIAL AND ECONOMIC ORDER
}

\author{
Dr. Lassana Toure ${ }^{1}$, Atoumane Diagne ${ }^{2}$ and Dr. Amadou Traore ${ }^{3}$ \\ ${ }^{1}$ Lecturer and researcher at the University of Segou, Email: lassana.toure@mesrs.ml \\ ${ }^{2}$ Statistical Engineer and Economist, Email: atoumane@live.fr \\ ${ }^{3}$ Lecturer and researcher at the University of Ségou, Email: tamadou8@yahoo.fr
}

Cite this article:

L. Toure, A. Diagne, A. Traore (2021), Impacts of COVID-19 on the World Economy and Societies: Towards a New Social and Economic Order. African Journal of Social Sciences and Humanities Research 4(2), 87104. DOI: 10.52589/AJSSHRYSQV3YOU.

\section{Manuscript History}

Received: 29 April 2021

Accepted: 18 May 2021

Published: 27 May 2021

Copyright $\odot 2020$ The Author(s). This is an Open Access article distributed under the terms of Creative Commons AttributionNonCommercial-NoDerivatives 4.0 International (CC BY-NC-ND 4.0 ), which permits anyone to share, use, reproduce and redistribute in any medium, provided the original author and source are credited.
ABSTRACT: This paper reports an analysis of the statistical data and a socio-economic impact analysis of COVID-19. The pandemic started in Asia, particularly China, in December 2019 and continued until it peaked there at the end of February 2020. Europe has seen a dramatic increase in the number of confirmed cases and deaths since March 2020. At the same time, and to a lesser extent, North America, including the USA, has gradually taken over and now contains more new positive cases than anywhere else in the world. In contrast, South America, like Brazil, was the epicentre of the pandemic at the end of August 2020. Africa and Oceania are modestly affected by the pandemic. Econometric estimates were made assuming that the COVID-19 pandemic continues until December 2021. The results show that the duration of the peak of the pandemic would not exceed 400 days worldwide, if during the first 24 months the number of new cases never exceeds 800,000, and in the absence of an effective vaccine and treatment. The measures currently being implemented in many countries to prevent the spread of the disease (social distancing, closing of markets, confinement, banning of gatherings, etc.) are having a profound impact on the various markets and, through them, on the living conditions of households. The number of unemployed may increase. World trade and world prices of financial assets are in free fall. The State and the Central Banks will be obliged to intervene to revive economic activity and regulate certain prices of necessity. This pandemic, through barrier measures, is causing new social developments across the planet. It emphasises the idea that science, techniques and technologies are largely limited. Health and social systems are gradually destabilised. The pandemic suddenly affects religions, socio-professional activities, cultures, the functioning of transport and consumption systems. A new social and economic order is gradually taking shape in place of individualism, notably with a return to communitarian values and the emergence of new behaviours.

KEYWORDS: COVID-19 Impact Analysis, Econometric Forecasting, Global Economy, Societies, New World Order 


\section{INTRODUCTION}

Worldwide, as of 30 April 2020, the pandemic Sars-CoV-2 virus has infected 151 million people and caused 3,200,000 deaths, according to figures from John Hopkins University. The most affected country is the United States (33.1 million cases and 589,000 deaths), followed by India (19.1 million cases and 210,000 deaths), Brazil (14.5 million cases and 400,000 deaths), France (5.6 million cases and 104,000 deaths), Russia (4.8 million cases and 110,000 deaths), Turkey (4.8 million cases and 40,000 deaths) and the UK (4.4 million cases and 128,000 deaths). Europe, including Italy, Germany, Poland and Belgium, appears to be the epicentre of the pandemic at the end of November 2020. We can speak of new waves of coronavirus contamination in European countries. In France, according to the Ministry of Health, on 7 November 2020, the coronavirus infected 86,852 new people confirmed by PCR test, an absolute record since the launch of large-scale screening tests, and caused more than 1,000 deaths in the following days. India is the new epicentre since March 2021. In South America, there has been a lull in recent months despite being the epicentre of the pandemic during July-August-September 2020: Argentina (2.9 million cases and 63,000 deaths), Colombia (2.8 million cases and 73,000 deaths), Peru (1.8 million cases and 61,000 deaths) and Chile (1.2 million cases and 26,000 deaths). The African continent has 122,000 deaths and 4,100,000 recoveries from 4,580,000 confirmed cases, with South Africa accounting for 1,580,000 cases and 54,000 deaths, according to the African Union's Centre for Disease Prevention and Control as of 10 November 2020. The speed of spread of the pandemic is very high.

The French media Le Monde wrote on its website on 26 February 2020

Donald Trump on Wednesday evening praised his administration's actions to fight the epidemic, such as restrictions on travellers from China. "Thanks to everything we have done, the risk to Americans remains very low," the American president said at a press conference at the White House. He intends to devote an "appropriate" budget to the fight against the virus and has appointed his vice president, Mike Pence, to coordinate it. (Le Monde, 26 February 2020)

The current global pandemic of COVID-19 appears likely to have consequences beyond the mere spread of the disease and containment measures. Some economic reports highlight supply shortages of manufactured goods and pharmaceuticals due to widespread factory disruptions in China.

In some hard-hit regions such as Italy and South East Asia, this has led to panic buying. The high-tech industry experienced delays in the delivery of electronic products. At the societal level, containment has had consequences for the social organisation of the population and positive impacts on biodiversity. "We are experiencing a kind of revolution of a new kind" (B. LATOUR, 2020).

Today, we have to adapt to a probable reconfiguration of capitalist society and a revision of our behaviour. Businesses, humans and non-humans alike are finding themselves in a core competency where agility is no longer an option, but an organisational imperative, in order to be able to develop new ways of thinking.

Given this situation, the aim of this paper is to analyse the impact of the COVID-19 crisis on the economy and society. The aim is to study the impact of this pandemic on the economy and 
society by consulting the current electronic literature and the statistical databases of various specialised organisations, after carrying out a statistical analysis of the pandemic and an econometric forecast of the cases tested positive for the coronavirus. This would help in the development of new socio-economic resilience strategies taking into account the evolution of the COVID-19 crisis and the post-coronavirus life.

\section{Study Methodology}

Three methods of analysis will be used in this study: Statistical analysis of the pandemic, Econometric forecasting of proven cases and Impact analysis of COVID-19.

\section{Statistical Analysis}

The analysis tools of Descriptive Statistics (mean, median, standard deviation, minimum, maximum...) will be used in this part to describe the situation of the pandemic at the end of August and beginning of September. Graphs of the evolution of the pandemic will be added to this panel of statistics.

\section{Econometric Forecasting}

This work is based on the study carried out by M. GRASLAND (2020), a statistician at ENSAI in Paris, by making a parametric estimate. The general idea is that the new confirmed cases and the new deaths of the coronavirus during a day follow the normal law, because we notice some similar properties:

$>$ A rapid rise in the number of cases with the onset of the new epidemic wave and its exceptional scale currently raging in Europe

$>$ A characteristic peak in the temporal centre of the epidemic.

The general objective is then to estimate the mean and standard deviation of the two normal distribution curves. Clearly, the mean of the normal distribution will correspond to a peak. The latter will correspond to one day, which will be the duration of the first peak of the pandemic. It is this peak that we want to calculate. Because if you multiply by two, you get directly the duration of the pandemic in the world.

Let $\mathrm{x}$ be the number of the day, $\mathrm{y}$ the number of new cases and $\mathrm{z}$ the number of new deaths during the day.

We count from 31 December 2019 each time to find out the date corresponding to the day's number. The peak of the first curve corresponds to the average number of new cases per day $\bar{y}$. Currently, at the time of the peak, there are almost 600,000 new cases worldwide. The peak of the second curve is the average number of new deaths per day $\bar{z}$.

When it comes to forecasting, one can always try to explain the paradox of results versus reality. Of course, one must also always assume the worst when making forecasts. Three scenarios are then posed:

- $\quad$ Trend scenario: number of new cases contained (below 600,000 cases per day)

- Realistic scenario: many new cases confirmed in late December 2020 or early January 2021 
- Pessimistic scenario ${ }^{1}$ : many new cases confirmed in late January 2021 or early February 2021.

Indeed, four unexpected situations can occur that can result in many more new cases (e.g. 800,000 new confirmed positive cases per day):

a) The emigrants decide by all means to return to their native country en masse;

b) The majority of states decide to deconfine populations, leading to new waves;

c) States begin mass screening with new positive cases

d) Foreign trade, including international trade, is picking up in all continents.

Another assumption in this methodology is that the pandemic continues until December 2021 (i.e. maximum 24 months of pandemic duration).

\section{Impact analysis}

The central question is to quantify the relationship between the level of development (economic and social) and the pandemic in the medium and long term (6 months to 2 years). On the economic level, the consequences of the health crisis on the real and monetary sphere will be explained, from a national and international point of view. In addition, sociology tries to give a positive explanation to everything that affects the life of men in society, after important upheavals that affect the individual because of the pandemic.

The COVID-19 phenomenon has unprecedented consequences for the economy and society. The following section presents the extent of its impact with an analysis of statistical data and a forecast of new cases of COVID-19 in the future.

\section{Statistical Analysis and Econometric Forecasting}

\section{Statistical Analysis of the COVID-19 Situation}

At the end of November 2020, the pandemic situation is as follows:

Table 1. Descriptive statistics of the situation of COVID-19

\begin{tabular}{lll}
\hline Statistics & Number of new deaths & Number of new cases \\
\hline Number of values & 316 & 316 \\
1st Quartile & 925 & 19494 \\
3rd Quartile & 5903 & 270061 \\
Minimum & 0 & 0 \\
Maximum & 10491 & 588725
\end{tabular}

\footnotetext{
${ }^{1}$ The resumption of the second epidemic wave in Europe during November and December 2020 can be integrated into this scenario
} 
African Journal of Social Sciences and Humanities Research

ISSN: 2689-5129

Volume 4, Issue 2, 2021 (pp. 87-104)

www.abjournals.org

\begin{tabular}{|c|c|c|}
\hline Scope & 10491 & 588725 \\
\hline Sum & 1264077 & 51796028 \\
\hline Median & 4674,5 & 122389 \\
\hline Average & 4000,244 & 161374,1 \\
\hline SE.mean & 148,2314 & 8132,337 \\
\hline CI.mean.0.95 & 291,6487 & 16000,56 \\
\hline Variance & 6943324 & $2.089863 e+10$ \\
\hline Standard deviation & 2635,019 & 144563,6 \\
\hline Coefficient of variation & 0,6587146 & 0,8958289 \\
\hline Skewness & $-0,2955518$ & 0,7651033 \\
\hline skew.2SE & $-1,077504$ & 2.789365 \\
\hline Kurtosis & $-0,9127674$ & $-0,06235251$ \\
\hline kurt.2SE & $-1,668996$ & $-0,1140116$ \\
\hline normtest.W & 0,9024039 & 0,9055122 \\
\hline normtest.p & $2.091444 \mathrm{e}-13$ & $3.659441 \mathrm{e}-13$ \\
\hline
\end{tabular}

Source: Authors based on data from Our World In Data (Oxford University), 10 November 2020

In total, by the end of November 2020, there were approximately 1,264,077 deaths worldwide with 51,796,028 confirmed cases of COVID-19. On average per day, we have 161,374 confirmed cases and 4,000 deaths with a standard deviation of 144,563.6 and 2,635.019 persons respectively. The median of new positive cases per day is 122,389 confirmed cases while for deaths it is around 4,675 deaths. This is summarised by a case fatality rate of $3 \%$ and a cure rate of $70 \%$ (see Figure 1). 


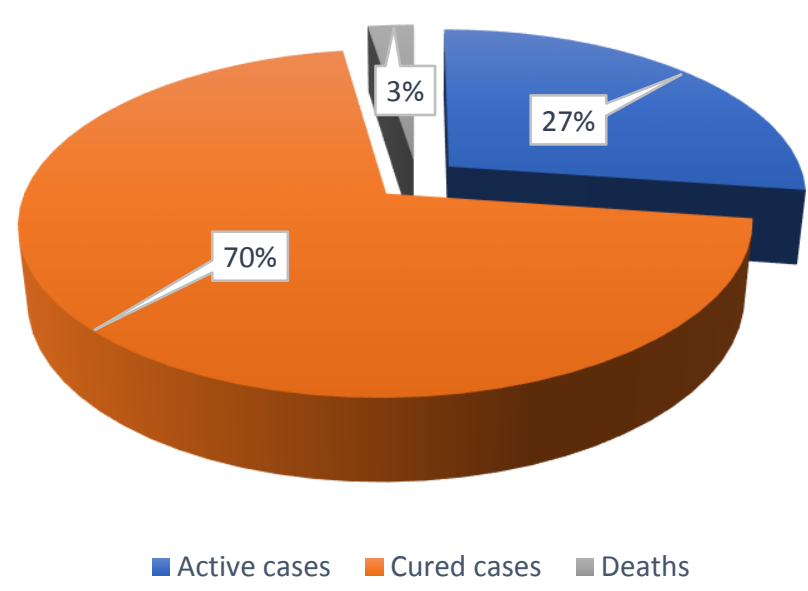

Figure 1: Hospital situation of the pandemic

Source: Authors based on data from Our World In Data (Oxford University), 10 November 2020

A comparison of total positive cases and deaths by continent yields the values shown in Figures 2 and 3. The pandemic started in China in December 2019 and continued until it peaked there in late February 2020. By the end of November 2020, Asia accounted for $28 \%$ of the total number of positive cases worldwide. Asia, including India and China, now has more positive cases than anywhere else in the world. Secondly, Europe has seen a dramatic increase in the number of positive cases since March 2020, reaching 15\% of the world's total positive cases. At the same time, and to a lesser extent, North America, including the USA, is gradually taking over $(24 \%)$. On the other hand, South America, following the example of Brazil, became the epicentre of the pandemic at the end of August 2020 with $24 \%$ of positive cases worldwide. Africa is modestly affected by the pandemic (about $4 \%$ of total positive cases), as is the continent of Oceania (less than 50,000 positive cases only).

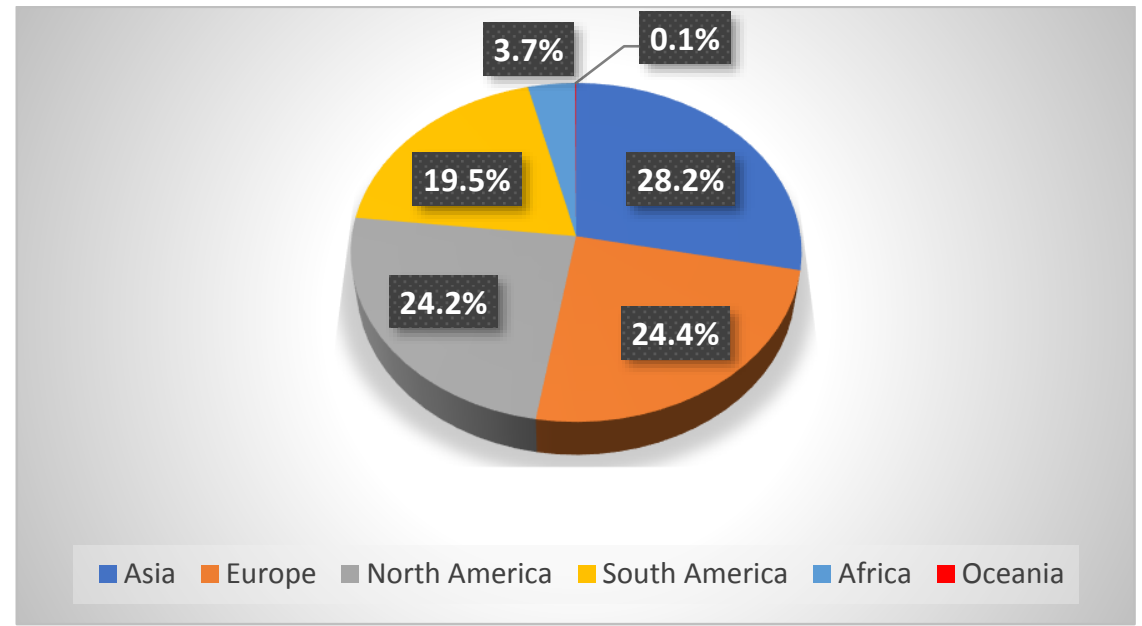

Figure 2: Distribution of confirmed cases by continent

Source: Authors based on data from Our World In Data (Oxford University), 10 November 2020 
The situation of deaths by continent is almost the same as that of confirmed cases as can be seen in figure 3 below (24\% for Europe, 20\% for Asia, 29\% for North America, 24\% for South America and less than $4 \%$ for Africa and Oceania combined).

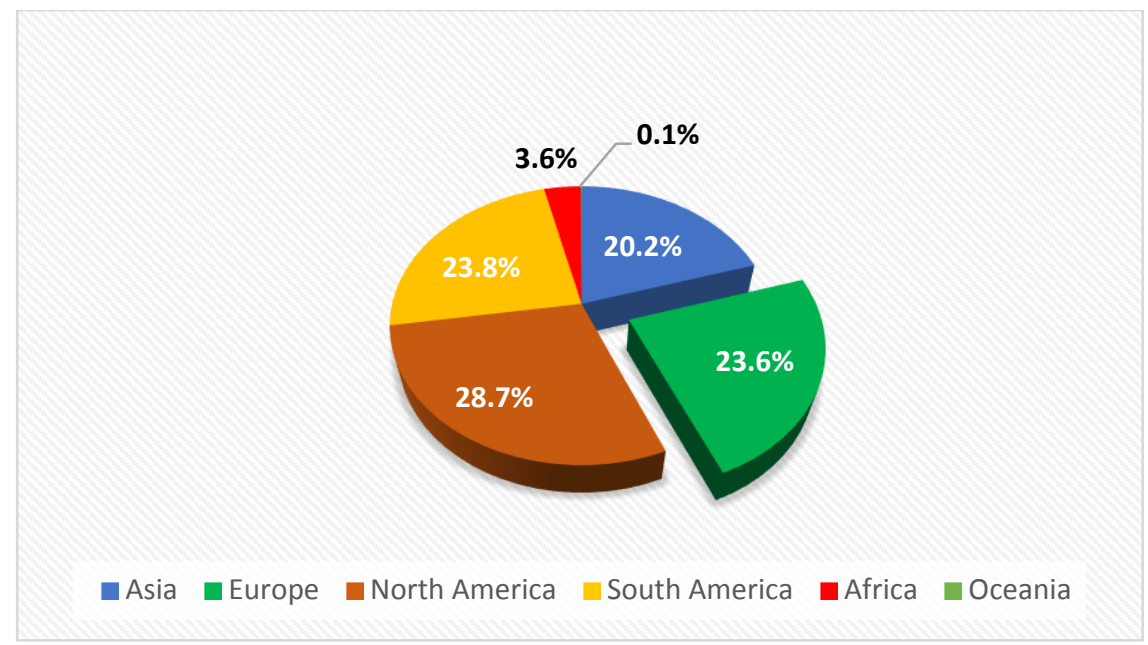

Figure 3: Distribution of deaths by continent

Source: Authors based on data from Our World In Data (Oxford University), 10 November 2020

If we analyse the most affected countries in terms of confirmed cases and deaths, we have the following figure 4:

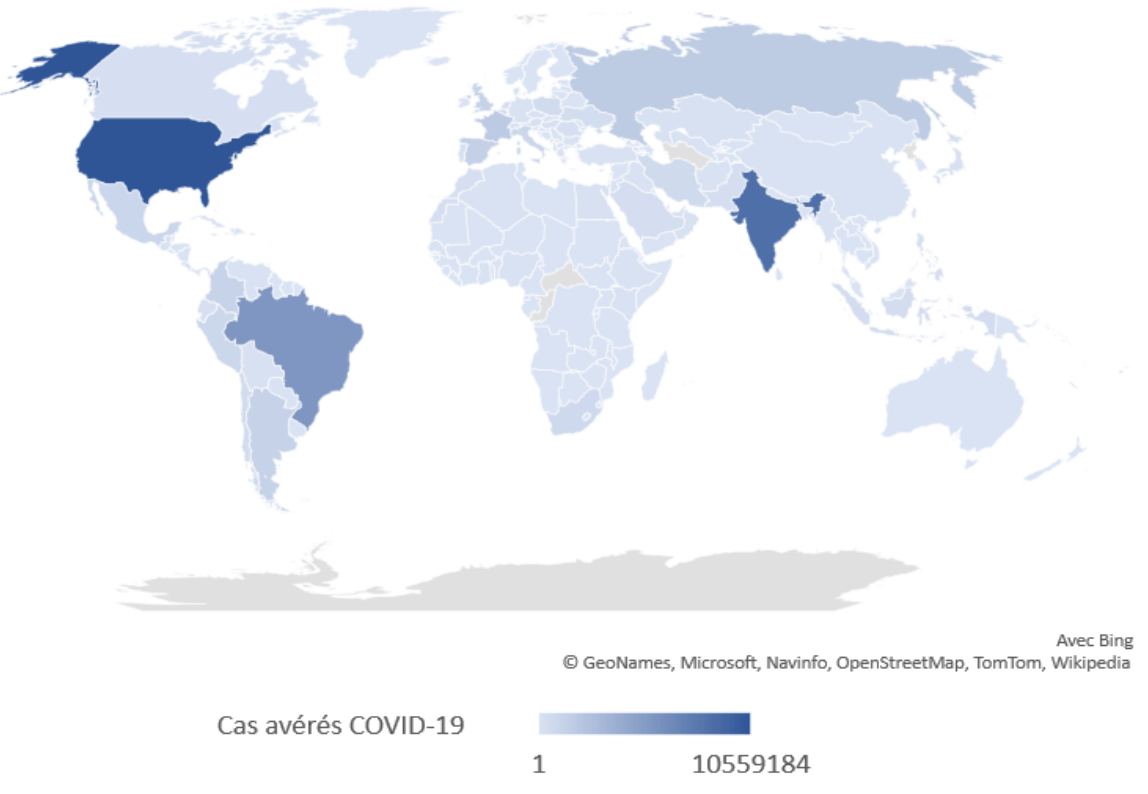

Figure 3: Status of COVID-19 in the world

Source: Authors based on data from Our World In Data (Oxford University), 10 November 2020 
The current pandemic trend was for the number of new cases to remain stable in JulySeptember 2020, followed by an unprecedented increase from October-November 2020, as shown in Figure 5. Indeed, the exponential increase in confirmed cases from March 2020 onwards continued until April 2020. By August 2020, the number of new cases has a stable trend as illustrated by the 14-day moving average curve (which corresponds to the theoretical incubation period of the disease).

Thus, the coronavirus is spread all over the world (normally in the human body) so that containment alone would not help. Only the vaccine and the medicine against this disease will do anything. Unless it is a global containment of the whole planet earth! This is impossible, knowing human beings. Keynes was certainly not only talking about consumption in his famous Basic Psychological Law, but about the needs of human beings who are always looking for satisfaction; they will not remain confined for the whole period of the pandemic, they will still have needs to satisfy.

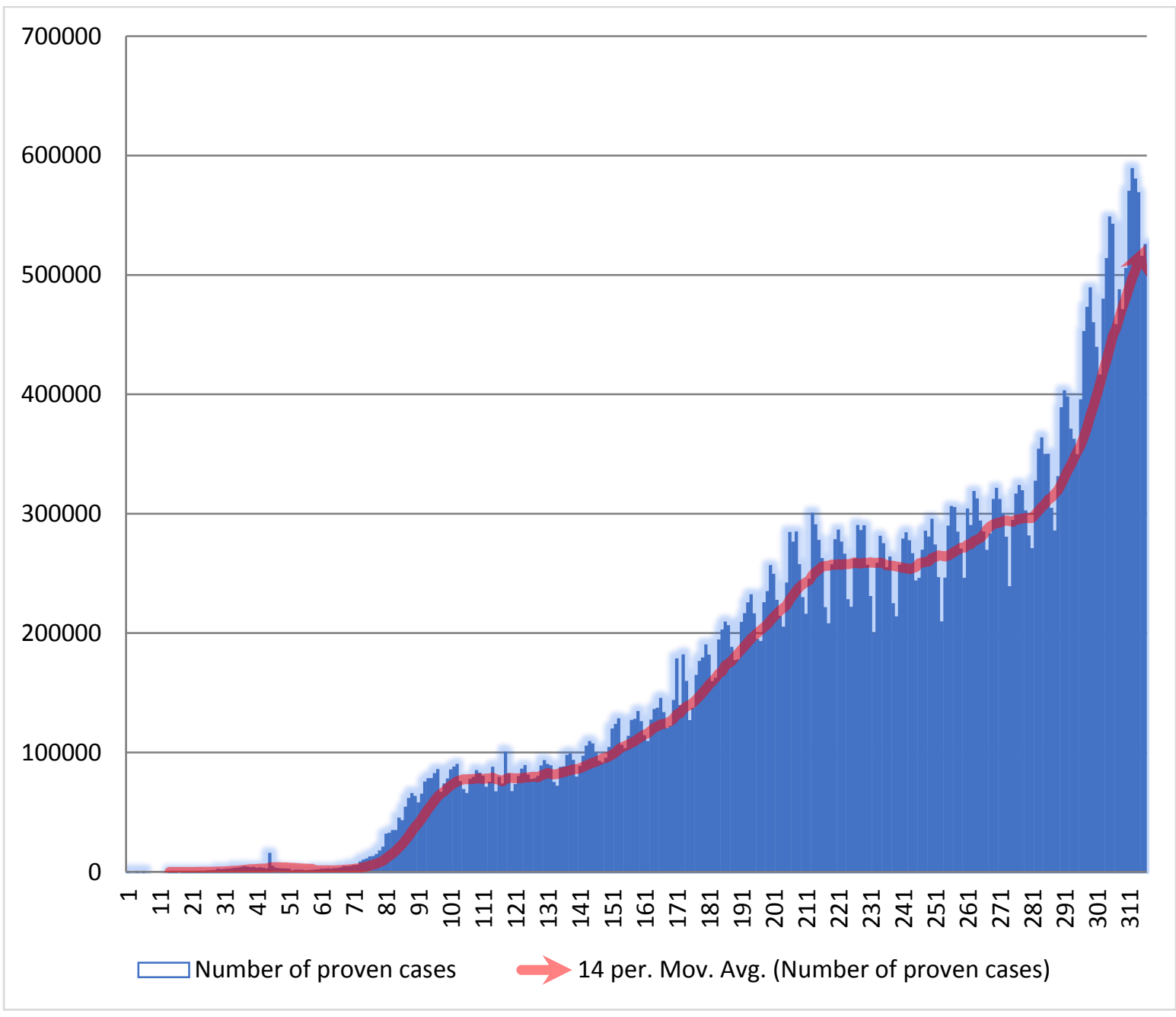

Figure 4: Evolution of new confirmed cases of COVID-19

Source: Authors based on data from Our World In Data (Oxford University), 10 November 2020 
In red Smoothing by period moving average 14

Also, people will adopt new habits and lifestyles. Indeed, even after 2021, COVID-19 will still be talked about in families and public spaces. Moreover, some infected people will not show any symptoms. Some may continue to say "Stay home" or "Stay alert" even after 2021.

Finally, if one is logical with oneself, and in the absence of an effective vaccine and treatment, the closure of borders should also continue even after 2021 because there will always be confirmed cases somewhere in the world (unless one is caught up with Keynes in the previous arguments). To say, the coronavirus story is just beginning.

The USA and some European countries, from the beginning of the pandemic, did not apply containment measures to people entering their territories, let alone curfews. It is certain that Africa will not be in the same situation as them. There will not be enough healthy infected or hospitalised cases to radically increase the speed of spread in the coming months, unlike in the USA, Europe, Latin America, etc.

\section{Econometric prediction of the duration of the pandemic}

With the descriptive statistics of the number of new confirmed cases and the number of new deaths, the maximum number of deaths and confirmed cases in December 2021 can be estimated according to the naïve Horvitz-Thompson Total estimate (assuming an equiprobable distribution of the two data sets):

- $\quad 161374.1 * 24 * 30=116189352$ confirmed cases on average

- $\quad 4000.244 * 24 * 30=2,880,176$ deaths on average

- $\quad 588725 * 24 * 30=423,882,000$ maximum confirmed cases

- $\quad 10491 * 24 * 30=7553520$ maximum deaths

This situation even takes into account the possibility of a new wave of the pandemic. And we can say that these are convergent estimators of the mean and the maximum.

Parametric estimates for the curve of new confirmed cases (normal distribution) give 360 days for the mean and 123,000 for the standard deviation, with an estimation error rate of 0.013492 (i.e. an estimate of 141,626,000 confirmed cases by December 2021) in the trend scenario (see Table 2). Estimates for the curve of new deaths (following a normal distribution) give 360 days for the mean and 200 for the standard deviation, with an estimation error rate of 0.02484847 (i.e. an estimate of 3,346,055 deaths by December 2021) in the trend scenario. With this, we can calculate the minimum and maximum number of confirmed cases and deaths expected for each date (from 0 to 720 days).

The estimates were made assuming that the pessimistic situation of COVID-19 continues until December 2021 (720 days). The results show that there would not be many new confirmed cases beyond this period in the peak scenario in late January 2021 - early February 2021 (see Table 2). It can be concluded that the duration of the COVID-19 peak would not exceed 400 days worldwide, if during the first 24 months the number of new cases never exceeds 800,000, and in the absence of an effective vaccine and treatment against COVID-19. Otherwise it would have been noticed during the first 24 months, and a new unpredictable scenario would be posed 
African Journal of Social Sciences and Humanities Research

ISSN: 2689-5129

Volume 4, Issue 2, 2021 (pp. 87-104)

www.abjournals.org

in this case. The peak will be reached towards the end of January and the beginning of February in the pessimistic scenario, as can be seen in the graphs of estimates (see Figure 7 and 8).

Table 2. Econometric prediction of the duration of the pandemic

\begin{tabular}{|c|c|c|c|c|c|}
\hline & Peak day & Error rate & $\begin{array}{l}\text { Standard } \\
\text { deviation }\end{array}$ & $\begin{array}{c}\text { Estimated } \\
\text { total }\end{array}$ & $\begin{array}{l}\text { Duration of } \\
\text { the pandemic }\end{array}$ \\
\hline \multicolumn{6}{|c|}{ Scenario 1 peak trend } \\
\hline $\begin{array}{c}\text { Forecasting } \\
\text { confirmed } \\
\text { cases }\end{array}$ & 360th day & 0,013492 & 123000 & 141626000 & 720 \\
\hline $\begin{array}{c}\text { Forecasting } \\
\text { deaths }\end{array}$ & 360th day & 0,02484847 & 200 & 3346055 & 720 \\
\hline \multicolumn{6}{|c|}{ Scenario 2 peak in late December 2020-early January 2021} \\
\hline $\begin{array}{c}\text { Forecasting } \\
\text { confirmed } \\
\text { cases }\end{array}$ & 370th day & 0,02254589 & 100000 & 172153000 & 740 \\
\hline $\begin{array}{c}\text { Forecasting } \\
\text { deaths }\end{array}$ & 370th day & 0,02485026 & 197 & 3485934 & 740 \\
\hline \multicolumn{6}{|c|}{ Scenario 3 peak in late January - early February 2021} \\
\hline $\begin{array}{c}\text { Forecasting } \\
\text { confirmed } \\
\text { cases } \\
\end{array}$ & 380th day & 0,02493961 & 100000 & 194160000 & 760 \\
\hline $\begin{array}{c}\text { Forecasting } \\
\text { deaths }\end{array}$ & 380th day & 0,02507685 & 212 & 3986542 & 760 \\
\hline
\end{tabular}

Source: Authors based on data from Our World In Data (Oxford University), 10 November 2020

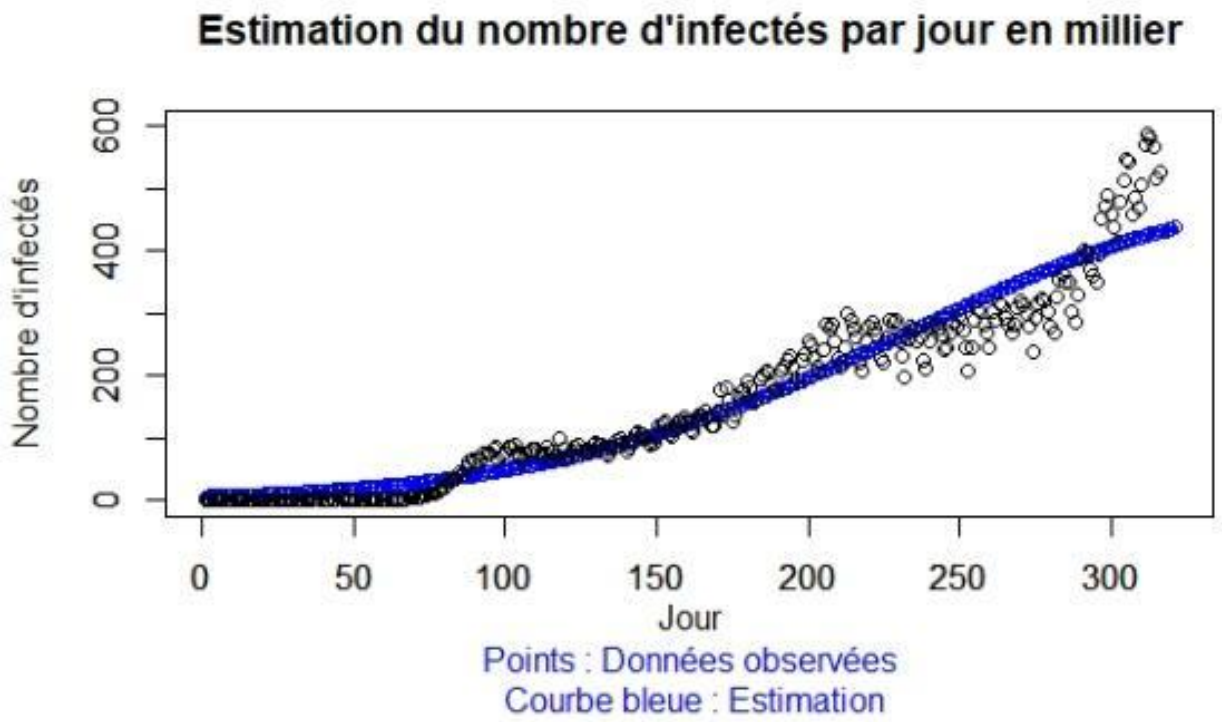

Figure 5. Peak Trend Scenario 1 of the Forecast of Confirmed Cases

Source: Authors based on data from Our World In Data (Oxford University), 10 November 2020 


\section{Estimation du nombre d'infectés par jour en millier}

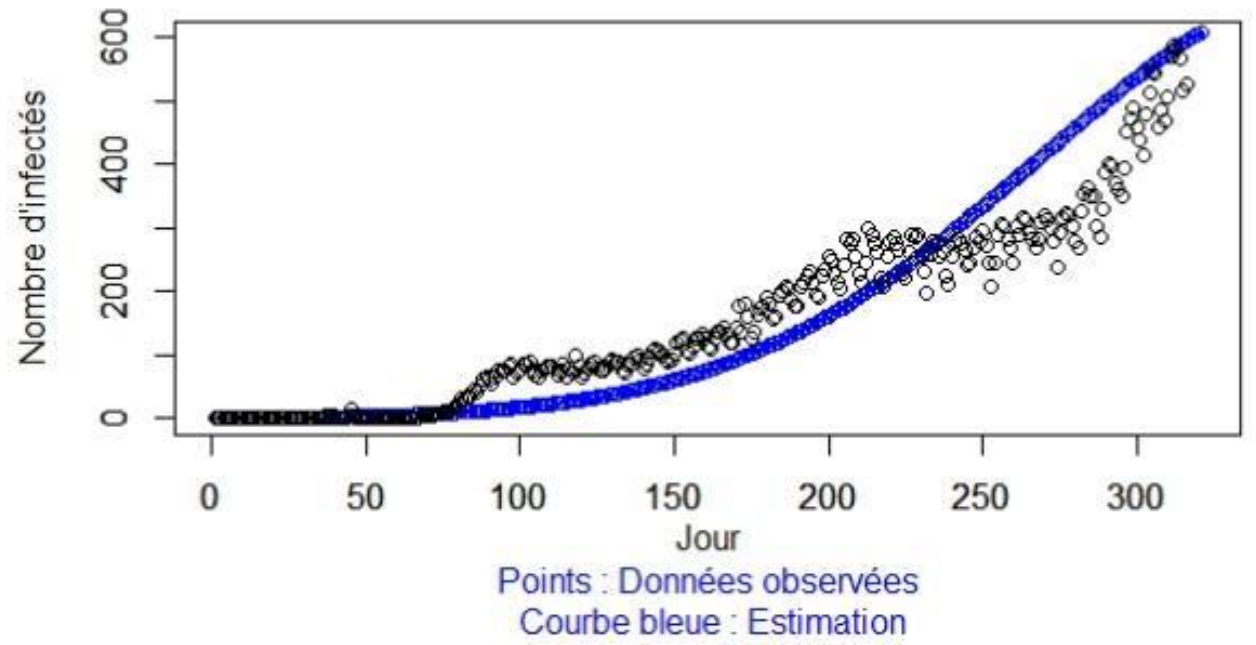

Figure 6. Peak scenario 2 in late December 2020 - early January 2021 of the Confirmed Case Forecast

Source: Authors based on data from Our World In Data (Oxford University), 10 November 2020

Estimation du nombre d'infectés par jour en millier

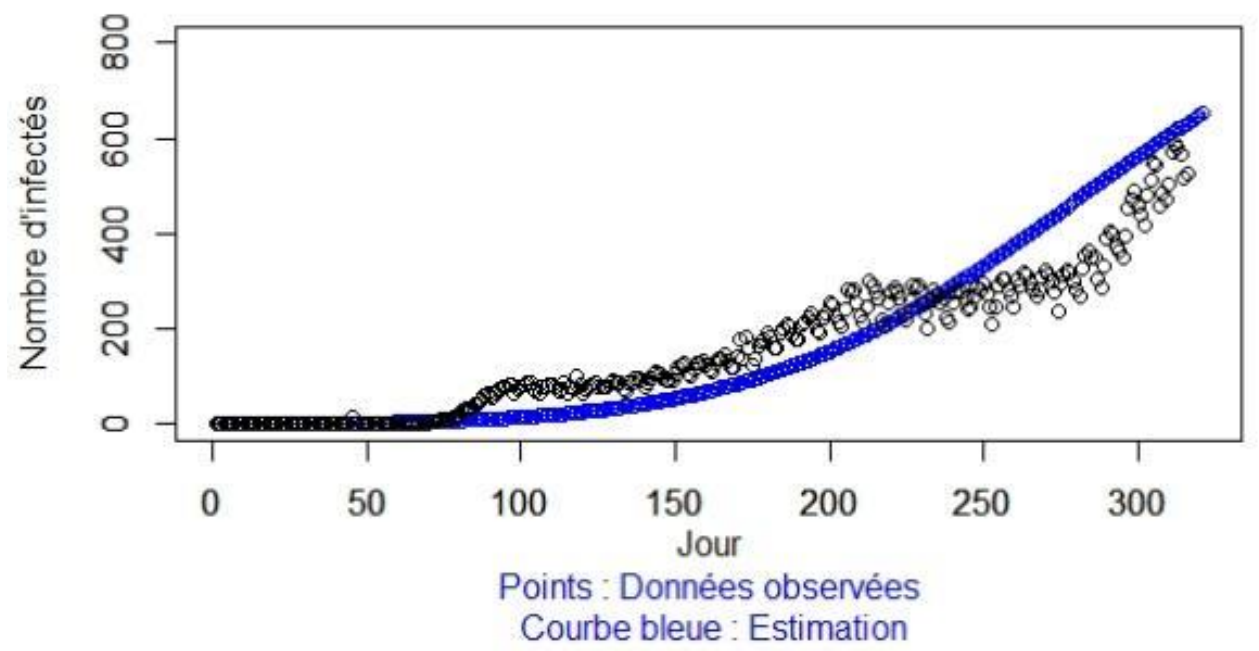

Figure 7. Peak scenario 3 in late January 2021 - early February 2021 of the Confirmed Case Forecast

Source: Authors based on data from Our World In Data (Oxford University), 10 November 2020 
It is clear that the first peak in deaths is already reached on day 108 (see Figure 9, 10 and 11). The peak in deaths is reached towards the beginning of May, which corresponds to about 11,000 deaths during the day. Indeed, the situation accelerated until the end of April. On the other hand, the cumulative death toll has been increasing until now.

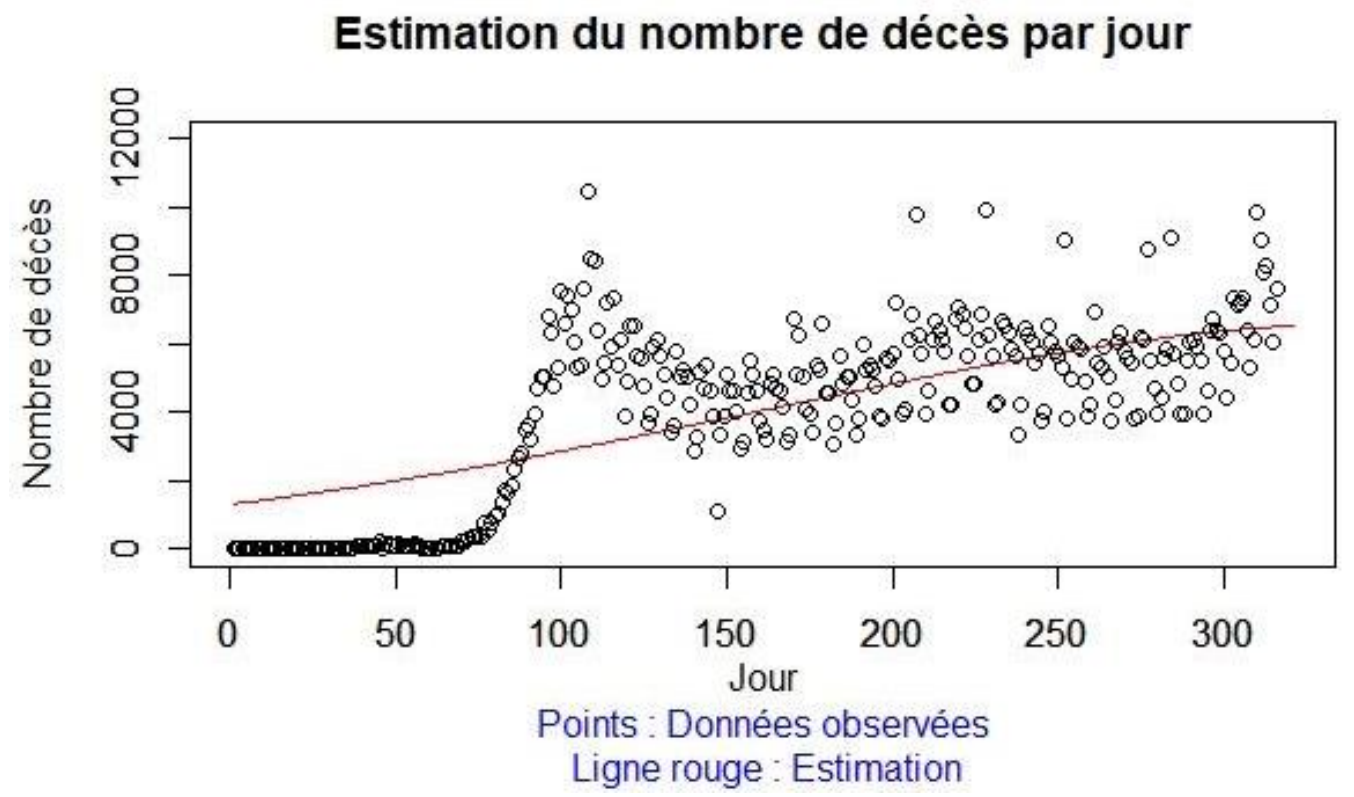

Figure 8. Peak trend scenario 1 of the Death Forecast

Source: Authors based on data from Our World In Data (Oxford University), 10 November 2020

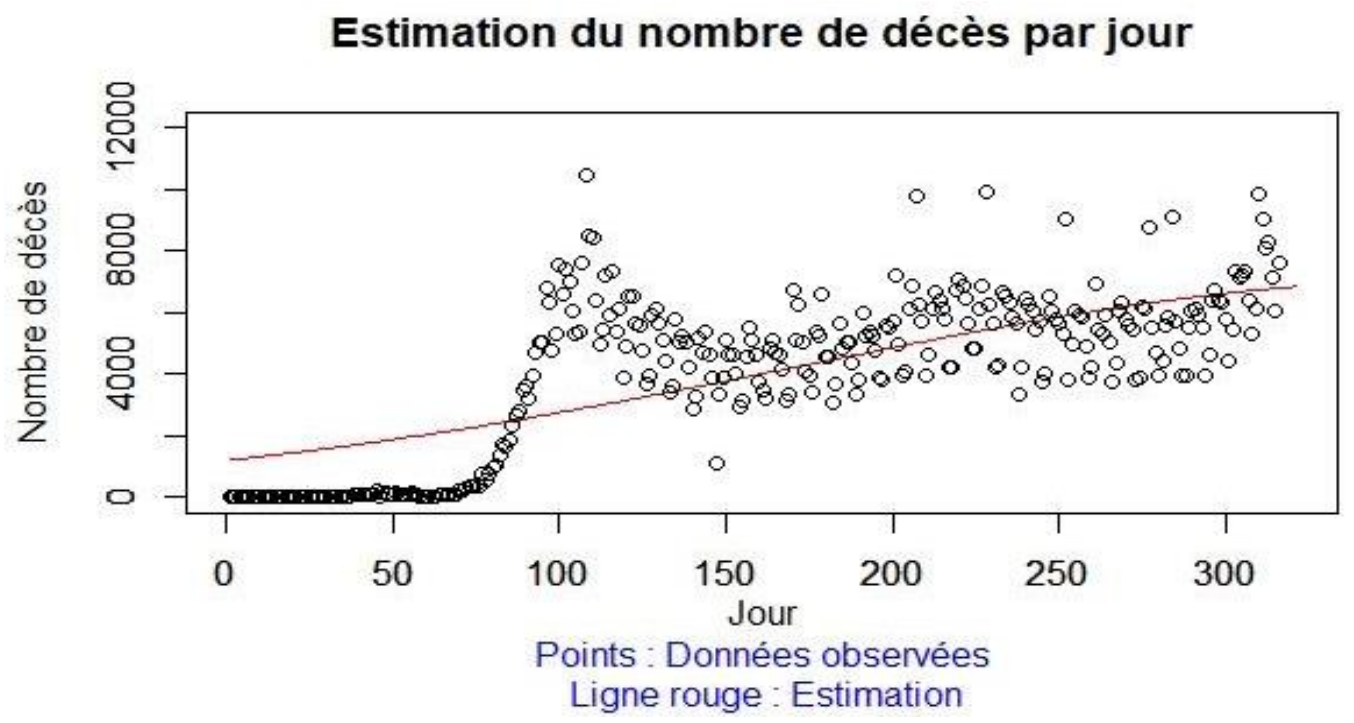

Figure 9. Peak scenario 2 in late December 2020 - early January 2021 of the Death Forecast

Source: Authors based on data from Our World In Data (Oxford University), 10 November 2020 


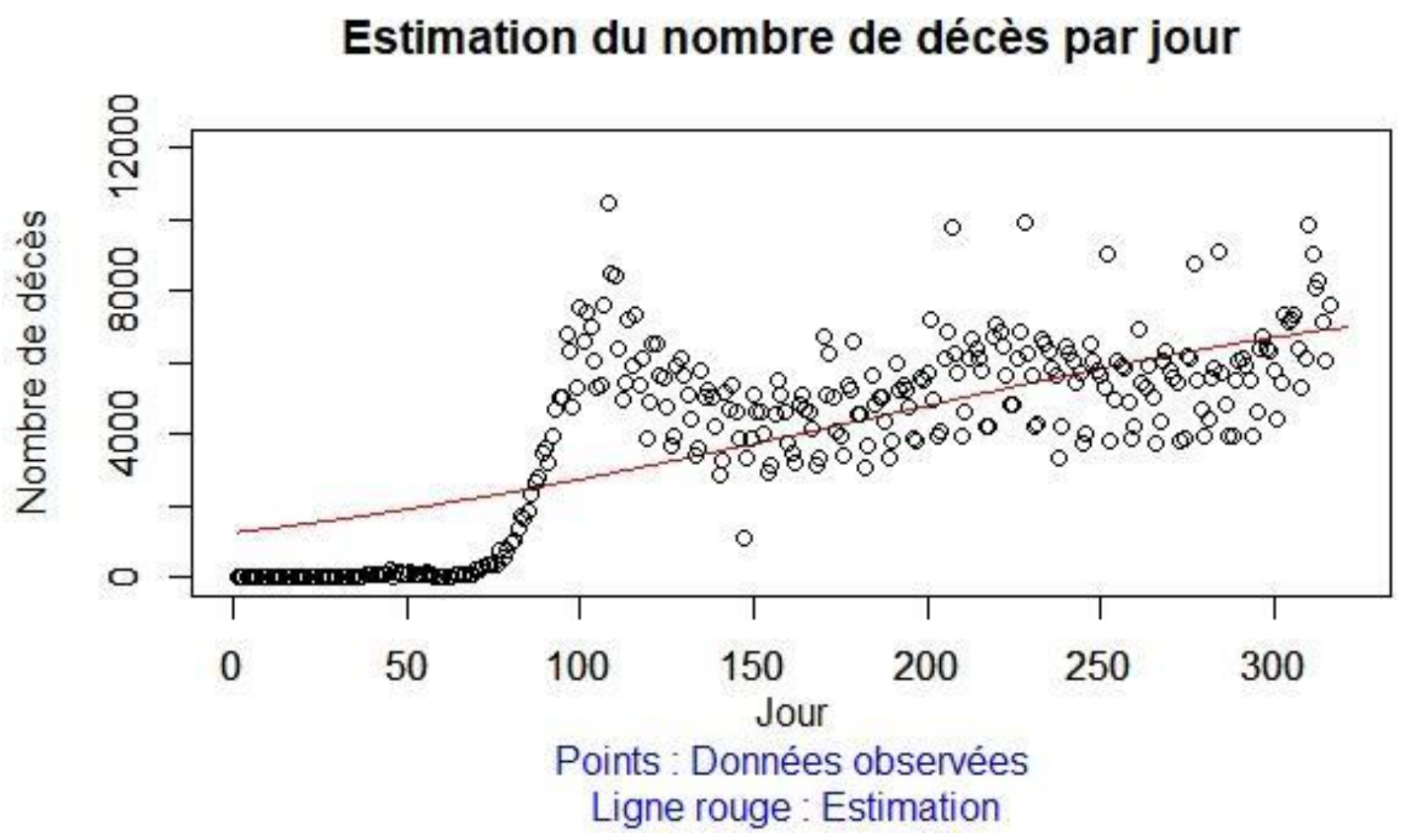

Figure 10. Peak scenario 3 in late January 2021-early February 2021 of the Death Forecast

Source: Authors based on data from Our World In Data (Oxford University), 10 November 2020

The duration of the pandemic could therefore reach 760 days for a total of 172 million estimated confirmed cases and 3 million deaths, of which the number of confirmed cases at the end of December 2021 could be between 141 million and 191 million people, including a maximum of 4 million deaths. After these 24 months, there will still be confirmed cases, but they will be negligible. Beyond this 760-day period, and in the absence of an effective vaccine and treatment against COVID-19, there will still be people hospitalised or new confirmed cases of one to 100,000 people per day in the world. The number of confirmed new cases will not be zero, right away. For China, for example, after the total containment in early 2020, there were a small number of cases as the days went by.

In any case, COVID-19 will have a negative impact on the economy and society, starting with the increasing death toll.

\section{Socio-Economic Impact Analysis}

\section{Impacts on Societies: A New Social Order, Poverty and Inequality}

Since November 2019, the world has been crumbling under the Coronavirus pandemic that is believed to have originated in the Chinese city of Wuhan. It is a contagious disease that spreads through simple contact between individuals. At a certain level of globalisation, industrialisation and technical and technological development, where the world becomes a global village, the spread of the disease internationally becomes instantaneous. If the equivalent of such a disease 
exists, it should be noted that at present there is no certified treatment for it. As a result, the disease is wreaking havoc around the world, defying even the strongest economies. The palliative solution to deal with this disease consists of measures such as washing hands with soap, wearing masks, respecting the social distance of one metre, confinement, stopping travel... The immediate effect of these measures throughout the world has been, in addition to the closure of borders, the closure of schools, shops, administrations, etc. The immediate effect of these measures across the world has been, in addition to the closure of borders, the closure of schools, shops, administrations, etc. Like an apocalyptic scene, unprecedented economic and social damage has been recorded on a global scale. This is one of the social issues that justify the very existence of the discipline of sociology, which attempts to give a positive explanation to everything that affects the life of people in society.

Indeed, society is made up of people interacting around the processes of survival and development. It manifests itself through the social, which determines social relations. At the heart of social relations is the individual, who represents the core. In society, we thus encounter microcosms, each individual being an interiority and a particular universe with a reasoning and a morality (M. WEBER, 2003). Immersed in the social, the moral aspects are more or less influenced by the interacting universes. At this level, individual behaviour is subject to social determinism. Socialising institutions such as the family, the school, the street, the media... are major actors for micro and macrosociological orientations. Concerning the macro-sociological level, we focus on culture. Indeed, the COVID-19 provokes a certain number of behaviours whose respect emanates from individual responsibilities and, by extension, from educational institutions. We question the influence of culture, education, and individual responsibility on the spread of COVID-19. These social factors are combined with the economics of families. The case of Japan is an example. Indeed, it is because Japanese culture is predisposed to containment, social distancing, cleanliness, etc. that this country has been relatively able to systematically control the spread of the virus.

If the spread of COVID-19 is through individuals. These individuals are the product of an educational and economic system, or by extension, a social culture. Thus, as social difference evolves, so does the pandemic around the world. So education can influence the evolution of COVID-19 around the world.

The COVID-19, through barrier measures, causes new social facts across the planet (E. DURKHEIM, 1895). It emphasises the idea that science, techniques and technologies are largely limited. Health and social systems are gradually destabilised. The pandemic affects religions, socio-professional activities, cultures, the functioning of transport and consumption systems. And it does so abruptly. A new social and economic order is gradually taking shape in place of individualism. This includes a return to communitarian values and the emergence of new behaviours. Individual freedom is gradually fading as we understand the harm it can cause. This question of freedom in turn becomes a controversial issue in some countries, including the USA. We are witnessing the genesis of a new social order imposed by nature.

As a result, the World Bank estimates that "between 88 and 115 million more people will fall into extreme poverty in 2020, meaning that between 703 and 729 million people will be living on less than $\$ 1.90$ a day. The extreme poverty rate will be between $9.1 \%$ and $9.4 \%$, which will put us back three years to 2017 levels. The situation is likely to worsen further in 2021, with an additional 23-35 million poor people, bringing the total number of new poor people to an estimated 110-150 million by then. Thus, the coronavirus crisis, combined with the 
consequences of conflict and climate change, is likely to trigger a cycle of impoverishment fuelled by rising income inequality.

\section{Economic Impacts: Recession, Unemployment and Debt}

The measures currently being implemented in many countries to prevent the spread of the disease (social distancing, closure of markets, containment, prohibition of gatherings, etc.) have a profound impact on individual markets and, through them, on the living conditions of households.

The primary channel for international transmission of the measures is tourism; the spending of more than 150 million Chinese who visited the world in 2018 exceeded $\$ 277$ billion according to the World Tourism Organisation ${ }^{2}$. The containment measures reduce trade to very little; Asian countries are the most affected. Thailand, which welcomed 10 million Chinese tourists in 2019, is the most affected with a 58\% drop in Chinese tourist arrivals in the New Year. The Thai government is not banning Chinese tourist entries, a position criticised by the public. According to the Thai Ministry of Finance, the drop in Chinese tourism could reduce growth from $3.3 \%$ to $2.8 \%$ in $2020{ }^{3}$ despite the stimulus measures taken by the Bank of Thailand, which lowered its rates, as did the Bank of the Philippines.

The International Labour Organisation (ILO) suggests that the number of unemployed could increase by 5.3 million in an optimistic scenario and by 24.7 million in a pessimistic scenario from a baseline of 188 million in 2019.

While workers in developed countries can partly rely on conventional social protection mechanisms and some income stabilisation schemes, the situation is much more worrying for workers in developing countries, the vast majority of whom work in the informal sector ( $\mathrm{F}$. GUBERT, 2020).

Whether they are street vendors, handlers or small-scale artisans, confinement, curfew or market closure measures mean that they are no longer able to work. They are then unable to ensure their daily subsistence, in contexts where there is often no pension, unemployment insurance or health insurance.

In addition, market-driven prices will fall continuously overall (e.g. the price of oil per barrel) over the period of the pandemic, affecting global production, which would automatically decrease. The price of a barrel of oil fell from 72 dollars in December 2019 to 22 dollars at the end of March 2020.

Global financial asset prices are in free fall. Central banks are injecting a lot of money to stop the downward trend of these world prices. However, bank credit cannot increase beyond the equivalent potential output. The production system is impacted by the COVID-19 to such an extent that companies globally have additional production constraints (labour factor, capital, technological means...).

Thus, the fall in overall production could have negative effects on wage levels. Wages are likely to fall for many workers, moreover in the very short term. The GDP of the world's major powers (USA with $\$ 21,345$ billion in 2019 ; China with $\$ 14,217$ billion; Japan with $\$ 5,176$

\footnotetext{
${ }^{2}$ https://www.unwto.org/fr/node/10067.

${ }^{3}$ Nikkei Asian Review, "Thailand keeps doors open to Chinese tourists", 10 February 2020
} 
billion; Germany with $\$ 3,964$ billion; India with $\$ 2,972$ billion; UK with $\$ 2,829$ billion; France with $\$ 2,762$ billion) is likely to fall. Economic forecasts for the year 2020 confirm this much feared recession: USA at $-5.9 \%$; Russia at $-5.5 \%$; Japan at $-5.2 \%$; Germany at $-7.0 \%$; SubSaharan Africa at -1.6\%; UK at -6.5\%; France at -7.2\% (IMF, April 2020).

In Africa, and surely everywhere else in the world, the state will be obliged to intervene to revive economic activity. This automatically leads to an increase in demand and in certain necessity prices. Inflation is moderate, however, because there is no longer the famous imported inflation from developing countries. International trade will come to a standstill.

Therefore, even with government intervention, the demand for goods and services in all countries is likely to fall further overall as long as the economic crisis lasts (including the demand for business labour). Of course, some companies will get the short end of the stick, but this will not generalise to global economic growth. In short, no matter how big or small, the consequences of COVID-19 will affect all sectors (education, society, transport, leisure, tourism...). Thus, only the end of the health crisis could allow economic activities to resume and not necessarily the state's recovery policy, which would only serve to ensure the survival of the population (Keynes' ideas should not be abandoned at this time). In any case, resources are scarce and needs are unlimited.

In the end, World Bank Group President David Malpass' address to the International Monetary and Financial Committee (27 March 2020) illustrates the situation on the financial sector, the banking sector in particular:

"In addition to its health consequences, the COVID-19 pandemic is expected to cause a severe global recession. Last Wednesday, I presented to the Board a $\$ 160$ billion package that will fund country-specific support activities to address the crisis over the next 15 months. These activities will focus on poverty reduction, with an emphasis on financing for reform and on protecting the poorest households and the environment.

Poor countries will be the hardest hit, especially those that were already highly indebted before the crisis. We are prepared to mobilise up to $\$ 35$ billion of IDA-19 financing in advance and make additional resources available. However, to achieve sustainable debt levels, many countries will need debt relief, which is the only option to enable them to devote any additional resources to the fight against the pandemic and to address its economic and social consequences."

\section{CONCLUSION}

When is the good news when the peak moves by geographical area? From China to Latin America, through Europe and North America, then South America, the peak seems to be going around the world. To the astonishment of some forecasters, Africa, the cradle of pandemics such as HIV-AIDS, Ebola, famines and wars, has so far been relatively spared. COVID-19 remains a socio-anthropological and economic mystery. All in all, despite the damage, the outlook remains bleak until there is a consensus on the means of treatment (over 172 million confirmed cases and nearly 4 million deaths expected by December 2021). New waves of coronavirus infection will result in historic peaks, requiring more restrictive measures worldwide. 
The following preventive recommendations remain in force for the fourth quarter of 2020 (October-December) and the whole of 2021:

1. Quarantine of any immigrant setting foot on the national territory

2. Strengthening security at land borders

3. Disinfection of all suspected contamination sites

4. A plan to quarantine returning migrants and provide them with economic and social support

5. Continuation of barrier measures and curfew

6. Gradual resumption of public investment in developing countries as a means of generating employment and economic growth

7. Boosting exports from developed and emerging countries for high value-added and high necessity products.

On a completely different socio-economic level, migrants, especially those who have not been regularised, remain in an uncertain situation, especially as the developed countries are in recession.

A new social and economic order is gradually taking shape in place of individualism. This includes a return to communitarian values and the emergence of new behaviours.

It can be concluded that the new world order calls for the control of state indebtedness and the design of a new economic model allowing for economic growth and better living conditions for the people. The post-pandemic economy could be less globalised, more digitalised and less egalitarian.

\section{REFERENCES}

DURKHEIM Émile, 1895, Crime et santé sociale, from Revue philosophique, 1895, 39, pp. 518-523. Reproduced in Émile Durkheim, Texts. 2. Religion, Morality, Anomie, pp. 173-180. Paris: Éditions de Minuit, 1975, 508 pp. Collection: Le sens commun.

GRASLAND Mathieu, 2020, Estimation of the duration of the COVID-19 epidemic, Working Paper, ENSAI Paris, p. 12.

GUBERT Flore, 2020, COVID-19: double economic punishment in sight for developing countries, Institute of Research for Development (IRD), https://theconversation.com/covid-19-double-peine-economique-en-vue-pour-les-paysen-developpement-136480 consulted on 10 November 2020.

KLAUS Nordhausen and HANNU Oja, 2018, Robust Nonparametric Inference, Annual Reviews of Statistics and its Application, volume 5, pp 473-500.

MASAYUKI Yuda, 2020, Thailand keeps doors open to Chinese tourists, Nikkei Asian Review, accessed 10 February 2020.

World Trade Organization, 2020, Press Release No. 855 of 8 April 2020. 
SINAPIN Marie-Noëline, 2020, The consequences of the COVID-19 pandemic on the socioeconomic and environmental sphere: what place for common utility as a basis for future agility? LITEM, Univ Evry, IMT-BS, Université Paris-Saclay, 91025, Evry, France.

WEBER Max, 2003, L'Éthique protestante et l'esprit du capitalisme, suivi d'autres essais, Paris, Gallimard, p. 173 (edited, translated and presented by J.-P. Grossein with the collaboration of F. Cambon).

Websites:

https://sante.journaldesfemmes.fr/maladies/2605417-coronavirus-france-carte-directdiscours-edouard-philippe-nouvelle-mesure-deconfinement-bar-restaurant-parcvacance-claude-goasguen-zone-verte-regle-100-km/ accessed on 27 May 2020

https://www.unwto.org/fr/node/10067 accessed on 27 May 2020

https://www.lemonde.fr/planete/live/2020/02/26/le-bilan-du-coronavirus-en-directundeuxieme-patient-est-mort-a-paris_6030908_3244.html accessed on 26 February 2020

https://www.worldometers.info/coronavirus/ accessed on 10 November 2020

https://www.lemonde.fr/idees/article/2020/03/25/la-crise-sanitaire-incite-a-se-preparer-a-lamutation-climatique_6034312_3232.html accessed on 10 November 2020

https://www.banquemondiale.org/fr/news/statement/2020/03/27/world-bank-group-presidentdavid-malpass-remarks-to-the-international-monetary-and-financial-committee accessed on 27 May 2020

https://www.ourworldindata.org/coronavirus-source-data accessed on 10 November 2020 https://www.sante.gouv.sn accessed on 02 June 2020

https://www.banquemondiale.org/fr/research/brief/poverty-and-shared-prosperity-2020reversals-of-fortune-frequently-asked-questions accessed on 10 November 2020

https://www.gouvernement.fr/info-coronavirus/carte-et-donnees accessed on 10 November 2020

https://information.tv5monde.com/afrique/coronavirus-en-afrique-quels-sont-les-paysimpactes-350968 accessed on 10 November 2020

https://coronavirus.jhu.edu/map.html accessed on 10 November 2020 